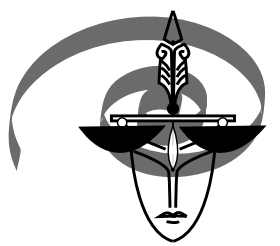

EUROPEAN

Volume $11 \cdot 2017 \cdot$ Number 2 (40)

DOI: 10.1515/ep-2017-0005

\author{
Bakhtiyar Aliyev* \\ Institute of Philosophy and Law \\ of the National Academy of Sciences of Azerbaijan \\ Baku \\ Azerbaijan
}

\title{
The Role of an Interpreter in Polygraph Checking
}

Роль интерпретатора результатов полиграфного тестирования

Key words: polygraph in Azerbaijan, polygraph examination with interpretation

As we know the implementation of translation is a psychologically complex activity, characterizes the work of an interpreter as a complex process of thinking and realizing a thought in two languages, which occurs when he performs his duties. The translation should be seen as a means of ensuring communication between people in cases where they do not speak the same language and are equally accessible to them. This security is the main goal and task, facing the translation and activities of the persons who implement it [Kashkin 1959: 141-142].

Conducting a conversation about the accuracy, maximality in translation, specialists often compare, or rather, compare the literal translation with the free (semantic) trans-

‘antiterror-baku@mail.ru 
lation, their relation to the languages participating in the translation [Dmitrenko 1971: 22-24].

On polygraph studies, the person conducting the study is competent to evaluate the translation performed. Only he can tell if the translation is full. The interpreter can only declare the accuracy of the translation he has done. The full value of translation is an important principle of the theory of translation. It has a number of essential features that make it possible to evaluate the translation in general.

It is important to note that the requirement of full value is presented to all types of translation carried out in various branches of knowledge and social life, including in polygraph checking. Naturally, the question arises: what translation for polygraph checking should be recognized as complete or accurate and how is this determined? Russian scientist L.N. Sobolev [1970: 143] provides three factors that affect the accuracy of translation:

1) the purpose of the translation;

2) the character of the material being translated;

3) the subject to which the translation is intended.

It seems that the factors pointed out by L.N. Sobolev to determine the "measure of accuracy" of the translation are unequal. In particular, the third point is questionable, since in all stages of the Polygraph Translation any tests are made equally, regardless of the persons for whom it is carried out. Indeed, the procedural status, nationality, profession, education, sex, age, etc. of persons who will be familiar with the translated texts do not affect their content. The essence of the translation does not change also from the fact that the presence of citizens is possible in the room.

The interpreter takes into account the personality, its features to the extent that they are reflected in the translated text, the composition of the speech (for example, when interviewing minors, age, education, etc. are taken into account).

The translation process for preserving and conveying the thoughts of the original must pass through and passes through a series of stages that consist in perception, comprehension of words in one language and reproduction of the result obtained on another. The exact translation is strictly dependent on the correct perception of the material to be transmitted by means of another language. For a correct interpretation of the original, translator is obliged not to smooth out the shortcomings of the source, not to embellish the translation itself.

In view of what has been said, it seems that to determine the measure of the accuracy of the translation, one should bear in mind:

A) the purpose of the translation; 
B) features of the translated text;

C) truthfulness and objectivity of translation.

The totality of these features will allow us to outline the limit of accuracy that is required in all types of translation. To make the translation precise and objective, that it can be defined as a full-fledged one, it is also necessary to solve the language problems that are concluded in accessibility, purity of speech, selection of linguistic means, usage, preservation of auxiliary means of speech.

Operating in two languages, the interpreter also solves questions of preserving auxiliary means of speech: intonation, inclination. In fact, they determine the nature of the speech impact on participants in Polygraphic Translation. In intonation, the most delicate and complex shades of emotions manifest themselves, and the speaker's condition is revealed in it: fatigue, excitement, confidence or self-doubt, etc. All this can not but affect the intonation of speech, which significantly affects the possibility of achieving that goal of influence to which the interrogator aspires to Polygraphic Translation. The intonation is, as it were, a mirror of behavior, reflects the attitude to the fact that is being reported. Consequently, the discrepancy of intonation with those psychological experiences that should have been manifested, for example, in the interviewee when giving testimony about certain circumstances, suggests their personality.

Translation, based on the features of the original and the situation where it is carried out, as well as the tasks assigned to it, presents various forms and types. Like the material being translated, it has the following forms: a) verbal, b) written.

Interpretation is carried out in two versions - synchronous and sequential, each of which is a two-way action.

At present, bilateral translation is widely used in various meetings, negotiations, conversations, and in legal proceedings (when interrogating witnesses, victims and other participants in the process who do not know the language of legal proceedings, in the speeches of participants in the process With applications, petitions, etc., when conducting experiments, inspections, searches.

Synchronous translation is not only the coincidence of the interpreter's speech with the speech of the speaker but also the uniqueness of the working conditions inevitably associated with the use of technical means and the constant intellectual tension and concentration of the translator.

To implement a full-fledged synchronous translation, an important factor is the correct definition of the location of the interpreter in the process of fulfilling his function. The first duty is to choose an advantageous position for listening to the original, 
which should be reported to the interviewee on the Polygraph Translation. As a rule, the interpreter chooses a place (which the author also believed from his own practice during the experiments conducted at the Institute of Philosophy, Sociology and Law of ANAS), between the negotiating parties.

In the translation practice seventeen "rules" of interpretation have been worked out (both in synchronous and consecutive translation), which differ from the written one. The analysis shows that they are not all acceptable when making a translation in the Polygraph Translation, so we will focus on some of them, which fully meet the requirements of interpretation and in Polygraph Translation:

1) the worst translation - better than no translation;

2) the translator must always have a loud confident voice, a clear reaction, selfcorrection in explicit form is not allowed;

3) the begun statement must necessarily be completed;

4) "ekanie" and "mekanie", etc., are inadmissible;

5) the interpreter translates only that which he is fully convinced (ie, that he confidently understands and can, correspondingly, express it well in another language). Everything else he either omits or replaces. But in the PFD, such omissions and substitutions are fraught with consequences, so the translator is given the right to ask again, clarify what he did not understand in order to carry out an objective interpretation;

6) the translation must necessarily feel the logical connection between the previous and the next. With this rule in Polygraph Translation also should be treated with care. The translator, at his own discretion, can not put on the shell of logic the incoherent speech of the interviewee. Here embellishment is unacceptable;

7) along the length of the translation and the original (almost) coincide;

8) in the translation it is necessary to use only stable word combinations, etc.

Polygraph examiners [Nabiyev 1979: 50-58] should remember that an interpreter is more than a written interpreter who is psychologically attuned to a relatively free treatment of the translated text. ${ }^{1}$

It should be noted that along with the oral translation in the PFD, a written one is also widely used. It is used as a translation of individual tests, and the materials of the case in general.

\footnotetext{
${ }^{1}$ Bekir Nabiyev, an Azerbaijani scientist and doctor of philological sciences, correctly notes in his article "The Language of Translation" that the liberty of an interpreter or his ignorance of the subtleties of languages from which and to which he translates leads to the fact that sometimes after the conversion he has completed, Original, even the absolute opposite is obtained.
} 
Written translation, being a document fixing the content of the translated material, allows checking the objectivity and completeness of the translation at any time, which is sometimes difficult in the case of an oral translation.

The interpreter should not try to guess how interrogated person could express this thought if he had mastered the language of legal proceedings. His task is to transfer the content of the facts, which is closest to the original. At the same time one should not strive for a literal translation.

To show the features of the translation in Polygraphic Translation, it is advisable to compare it with the art translation. Moreover, in the Polygraph Translation, it is necessary to translate not only texts relating to different branches of knowledge, but also texts of conversations, various questionnaires.

It should be noted that the conditions for implementing a translation in the Polygraph Translation are specific and sharply different from those available in other areas of activity. The translation takes place in the official, often in a psychologically tense environment. The translator sometimes has to work with people who have suffered severe physical or mental trauma in a complex mental state. Sometimes the place of work is medical institutions, places of crime, etc. However, from an interpreter, always, under any conditions, a quick reaction and constant switching of thinking from one language to another are required.

There are certain signs that distinguish the conditions for the implementation of translations: 1) the possibility of self-selection of the text; 2 ) the time for the translation; 3 ) availability of qualified cadres of interpreters and the ability to monitor their activities. Let us consider in more detail and make a possible comparison of these features.

An interpreter who carries out an artistic translation, himself pre-schedules or agrees with the recommendation to translate a certain work, has a real opportunity to get acquainted with its content in advance and in detail. Having weighed his knowledge in the field of the original language, the interpreter takes up the matter or refuses it.

As for these actions in the field of Polygraphic Translation, for an interpreter they are often unexpected. The specialist can not get acquainted with the content of any procedural documents in advance and receives such an opportunity only after his appointment as an interpreter. He has to translate different materials, sometimes dealing with an abundance of terms that are first encountered.

Very often in Polygraphic Translation, there are texts saturated with lexical means that lie beyond the limits of the literary language, which are not widely used and are not widely known to the majority of the population, limited by the framework of any nar- 
row sphere. Naturally, therefore, when a participant in a criminal process turns to the life of a public "bottom" - the underworld - his speech begins to abound with argotic (slang) words and expressions, which immediately poses a difficult task for an interpreter. Persons faced with the need for a translation in law enforcement should have in mind that argo is a very peculiar lexical system, which, taking as a basis the vocabulary of the national language, and also dialectal, changes it almost beyond recognition through intensive use of the entire arsenal of word-building means of the language. Moreover, argo is widely used in foreign borrowings and, as a rule, such, which are unknown to the literary language.

It is also necessary [Nochevnik 1988: 32] to understand the mistakes of an interpreter related to the translation of facial expressions and gestures of participants in the Polygraph Translation. ${ }^{2}$ Often translators generally miss the translation of facial expressions and gestures, counting on the fact that the injured person also sees them and can come to the appropriate conclusions himself. However, the interpreter forgets that facial expressions and gestures become understood in conjunction with speech. At the same time, sometimes every gesture or facial expression can mean an independent thought. For example, when a person is interviewed, the person says that his accomplice from a distance made a gesture to kill someone, that is, he rubbed his hands over his throat or imitated a blow with a hammer on the head. The respondent can tell in his own words or imitate them as he remembered, and the interpreter needs a clear translation of the content of the episode. As we know in the production of polygraph studies, with the participation of persons who do not speak the language on which the Polygraphic Translation is conducted, the participation of an interpreter is necessary. He is one of those who provides the necessary conditions for establishing an objective fact in the case. Thus, the comparative analysis makes it possible to distinguish the following generalized features of an interpreter:

1) mastering the languages, from which and to which the translation is made

2) disinterest in the outcome of the case

3) appointment by the person making the Polygraph Translation

4) entry into the case, if any of the participants does not know the language of the proceedings

5) competence

\footnotetext{
${ }^{2}$ In our opinion in literature, it is not without justification that it is noted that "the language and the gesture accompanying it have a pronounced national and racial character, connected with ethnic, geographic, professional, social, role, cultural environment." This means that the word without gesture sometimes, in harmony with it and helping it to incarnate, to acquire meaning, as it were emptying, loses its sound.
} 
6) incompatibility of the translation function with other functions in the legal proceedings. In addition, from the general rules on procedural and general legal incapacity there is also such sign as:

7) the person reaches a certain age [Rakhunov 1961:268] $]^{3}$

Preparation of an interpreter for the performance of his functions. After appointing a person as an interpreter, it is necessary to prepare him for the performance of his function in the PFD. In the literature, this question is almost not considered. In the meantime, it is necessary to prepare him to fulfill his obligations and realize the powers in the Polygraph Translation in order to avoid unnecessary substitutions and to prevent or eliminate violations that can be committed by an interpreter. It is necessary to draw parallels between the participation of an interpreter in criminal proceedings since there is as yet no legal regulation of the participation of an interpreter in the Polygraph Translation. For this, as well as in criminal proceedings, in the Polygraph Translation it is necessary to clarify to the interpreter that: the interpreter is obliged to carry out the activities provided by law (interpreting during the investigative action and translating the investigative and judicial documents, into the polygraphic translation of the test questions and Conversations);

He has no right to carry out any orders from the side of the victim, the accused and other participants in the process, bypassing the investigative and trial bodies (in our case the polygraphic examiner); ${ }^{4}$

It is inadmissible to disclose the data of the preliminary investigation without the permission of the person conducting the investigation, the investigator or the prosecutor, in which case a subscription with a warning of liability under the relevant art. Of The Criminal Code of the Republic of Azerbaijan or the Criminal Code of Ukraine; 5

The interpreter has no right to express his opinion to the accused, victim, witness about the completeness and truthfulness of their testimony, and even more to reproach, to shame them if, in his opinion, someone gives untrue impressions. Not the interpreter, but the person making the inquiry, the follower, the court assesses the evidence according to its own internal belief, based on a comprehensive, thorough and objective

\footnotetext{
${ }^{3}$ At this point R.D. Rakhunov drew attention.

${ }^{4}$ Of course, the participants in the process have the right to apply to an interpreter on issues arising from the task of protecting their legitimate interests. For example, to detail, specify a certain part of the transfer, etc. But these appeals are carried out only through the body (official) who conducts proceedings on the case at this stage, or with his permission. Consequently, these contacts are procedural inform.

${ }^{5}$ This should be done not only about the materials of the translation, but also any data of the case, which became known to the interpreter during his participation in investigative and judicial actions or presence in the office of the investigator, judge, in the courtroom, etc.
} 
examination of all the circumstances of the case in their totality, guided by law and legal awareness. The task of an interpreter is to fully and accurately translate testimonies to create conditions for such an assessment, regardless of your own attitude to the form and content of what is being said. ${ }^{6}$

Preparing an interpreter for the performance of the functions assigned to him means that the person who conducts the inquiry, the investigator (prosecutor) and the court must explain to him not only his duties, but also his rights. [Larina 1986: 1] $]^{7}$

\section{The question of the psychological preparation of an interpreter for participation} in the Polygraph Translation. Meanwhile, the success of an interpreter in his work on Polygraph Translation largely depends on his correct decision. We can not discount the likelihood of a psychological influence on the interpreter of the experiences of the accused [Soloviev, Tsentrov 1986: 45-53, 64-71; Ratinov, Efimova 1988: 44-51] the victim, etc., the more targeted attempts of these individuals or relatives to evoke his sympathy. ${ }^{8}$ As a result, it is possible that an interpreter may have emotions that may affect the objectivity of the translation; Feelings of pity in connection with the age of adulthood, the family situation of the accused or, conversely, hatred and contempt in connection with the brutality shown by him at the time of the crime, etc. To avoid this, the person making the Polygraph Translation does not confining himself to a formal acquaintance of an interpreter with the content of the articles of the Criminal Procedure Code of Ukraine or the Criminal Procedure Code of Ukraine on his activities, upon presentation of the relevant document of appointment in this capacity, he should explain to the interpreter the duty to approach the case not with accusation or excuse, but only from the position of the function entrusted to him.

When interrogating through an interpreter, the person who produces the VFD is obliged to explain to the interpreter also that, if the questions and answers of the interviewee are unclear, he has the right to ask again in order to clarify their content.

\footnotetext{
${ }^{6}$ At the same time, without prejudice to the accuracy of the transmission of the content of oral and written speech, the interpreter has the right to transmit several provisions in one sentence, omitting interjections, linguistic words, and so on. He is allowed to squeeze, with the "addressees" of the transfer and the personcarrier of the information being translated, to seek, by asking, an adequate terminology. By not comment on the content of the translated information, emotionally emphasize those or other aspects. At the same time, if the "addressee" of the translation asks the question, with which place of the testimony, the speeches were associated emotionally expressed experiences of the person whose speech is translated, the translator must inform it.

${ }^{7}$ In this context, the opinion of A. M. Larina that "to ensure the exercise of rights - means to create the conditions necessary and sufficient for the rights holder to use them. One of these conditions is knowledge of one's rights. From this point of view, the explanation of rights is one of the elements of the security system."

${ }^{8}$ On the psychological state of the accused, the victim and the specificity of their interrogation.
} 
In turn, the interviewee should say that the interpreter has this right and it is not a manifestation of bias at all. At the same time, it should also be explained that the interpreter does not have the right to ask questions to the interviewee on his own initiative, since his function is only to translate questions from the interviewer and the respondent's answers. Finally, in the content of the training of the person appointed by the interpreter, to the specifics of his actions (especially if he is invited for the first time), in our opinion, includes familiarization with the peculiar psychological conditions, (conflictual relations, participants of Polygraph Translation, the apparent contradictoriness of their interests, the pressure of time, the danger of attempts of pressure, the tying of familiarity with stakeholders, etc.).

Equally important [Levi, Pichkalevi, Selivanov 1987: 24] is the problem of exercising control over the activities of an interpreter i.e., for the observance by him, the requirements, completeness and accuracy of the translation. ${ }^{9}$

It must be said in this regard that a reliable assessment of the interpreter's conscientiousness is a rather difficult task.

Here I recall the replica of Nikolaeva Irina Nikolaevna to my question about the participation of an interpreter in the Polygraph Translation, when I studied at the Polygraph School in Krasnodar (Kuban State Technological University). Then she said: "If you believe in an interpreter, you can invite him to Polygraph Translation." After all, "the activity of an interpreter is most difficult to control and verify." Moreover, some practical workers generally deny the possibility of monitoring (checking) the work of an interpreter. Especially this opinion of practitioners is widely applied to cases of participation in the process of a person who understands the signs of the deaf or dumb (deaf-mute).

To verify the correctness of the translation, carried out by a person who understands the signs of the deaf or dumb, it is recommended to use a video recorder.

A knowingly incorrect translation can be found when acquainting the accused, the victim, the civil plaintiff and the civil defendant with all the materials of the case (articles 220-222 of the Code of Criminal Procedure of the Republic of Azerbaijan). The specified participants of the process, having sufficient time to get acquainted with all the materials of the case, can discover the distortions committed in translating their

\footnotetext{
${ }^{9}$ In our opinion, the issue of procedural norms for monitoring the activities of an interpreter in criminal proceedings should be resolved at the legislative level. In this case, we consider the proposal of AA Levi, GI Pichkaleva quite well-founded. NA Selivanov, that in general during interrogation of persons with the participation of an interpreter, a sound recording should be used. This, of course, will allow us to further verify the reliability and quality of the translation.
} 
testimonies, documents, etc. ${ }^{10}$ Undoubtedly, the specificity of the profession of an interpreter [Rezker 1978: 41], especially in legal proceedings, requires and will always require systematic, independent work, continuous and persistent improvement of his knowledge, skills and habits. ${ }^{11}$ This makes it necessary to create a translation bureau and, on their basis, conduct professional training and retraining of interpreters, improving their knowledge in the field of jurisprudence. ${ }^{12}$

In the literature it is noted that "when choosing an interpreter, one should apply to state institutions, public organizations, institutes, special educational institutions, etc." and only in case of impossibility to invite a specialist from there can resort to the services of individuals. However, the enumeration of state and public institutions and organizations where one can find an interpreter does not solve the problem of his search, since in each case the person making the Polygraph Translation is forced to look for a specialist who meets the procedural requirements, at least in the named collectives. And it is quite possible that there will be those who can be invited as an interpreter taking into account the circumstances of the concrete case. It is no accident that the above recommendation provides for the possibility of resorting to the services of individuals. Obviously, such a search can almost randomly invite people who actually do not meet the requirements for the interpreter. The practice of law enforcement bodies shows that even in the absence of a translation bureau, there is a real opportunity to avoid inviting casual, incompetent persons as an interpreter.

Of course, the difference in the degree of qualification and talent of persons allowed for translation in the Polygraph Translation can not be eliminated. But those who are engaged in this, it is necessary to develop beforehand skills and skills sufficient to fully and accurately translate as applied to the tasks of Polygraphic Translation.

The development of the organizational and methodological foundations of the transition in the Polygraph Translation would help prevent violations not only of the principle of the national language, but also of other democratic principles.

Thus, the best organizational form and means of improving the organizational, methodological and scientific support of the functions of an interpreter is a translation bureau for criminal and civil cases, including Polygraphic Translations. By maintaining

\footnotetext{
${ }^{10}$ A similar possibility arises when acquainting with the materials of the case after the accused is brought to trial.

${ }^{11}$ We agree with Ya. I. Rezker that such independence is especially needed for a beginner translator who, of course, lacks the skills and vocabulary is still not large.

${ }^{12}$ Such bureaus exist in the central offices of law enforcement bodies in Moscow, which do a great job, serving only themselves, and because of the small number of staff, they do not have the opportunity to assist the investigative and judicial bodies.
} 
a constant relationship with the preliminary investigation and the courts, this institution will be able to ensure the challenge of competent interpreters in the light of the specifics of concrete cases and will give advice on disputable issues arising in the course of the translation in the proceedings.

At the bureau, courses, attestation commissions can be organized. For the investigative and judicial bodies, they will maintain a file of persons who, according to their competence, meet the requirements for an interpreter in court proceedings. The establishment of a translation bureau within the International Association of Polygraph Analysts seems to be an urgent need for justice, and the earlier it is organized, the more it will benefit the interests of ensuring legality and justice in the proceedings and in the Polygraph Translation. In the presence of such bureaus, many lawyers, philologists and international translators could help legal proceedings and the Polygraph Translation in carrying out important tasks of combating crime, ensuring the protection of human rights that do not speak the language of the proceedings.

\section{References}

Kashkin I., 1959, Interpreter, as a Critic and Criticism of Translation. Mastery of Translation. Sat. Articles, M., 141-142.

Dmitrenko V.A., 1971, Maximality in Translation / Notebooks of the Interpreter, M. No. 11, 22-24.

Questions of Theory and Methodology of Educational Translation, 1970, M., 143.

Nabiyev B., Culture of Language, Issue III [in Azerbaijani], Baku, 50-58.

Nochevnik M.N., 1988, Human Communication, Moscow, 32.

Rakhunov R.D., 1961, Participants in Criminal Procedure, M., 268.

Larina A.M., 1986, Investigation in the Criminal Case: Procedural Functions, M., 61.

Soloviev A.B., Tsentrov E., 1986, Dopres on the Preliminary Investigation, M., 45-53, $64-71$.

Ratinov A.R., Efimova N.I., 1988, Psychology of Interrogation of the Accused, M., 44-51.

Levi A.A., Pichkalevi G.I., Selivanov N.A., 1987, Receipt and Verification of Testimony by the Investigator, M., 24.

Rezker Y.I., 1978, On the Independent Work of a Beginner Interpreter, Tet-for the Sake of an Interpreter, M. No. 15, 41. 
